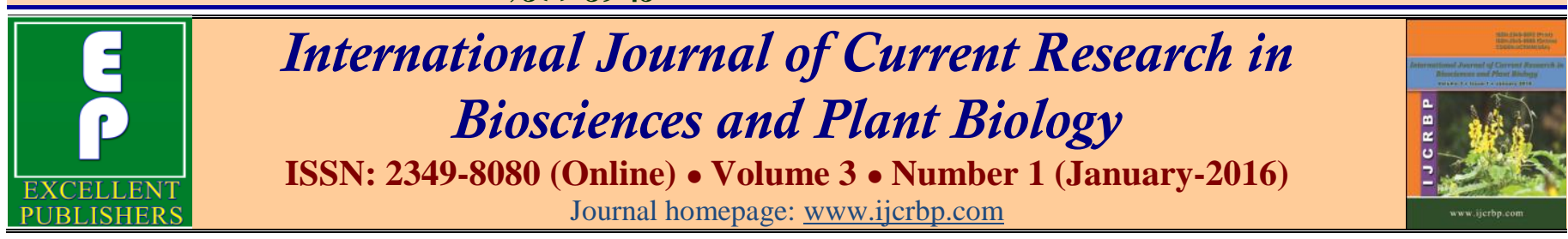

\title{
Bioethanol Production from Corncob Hydrolysed by Cellulase of Aspergillus niger Using Zymomonas mobilis and Saccharomyces cerevisiae Isolated from Palm Wine
}

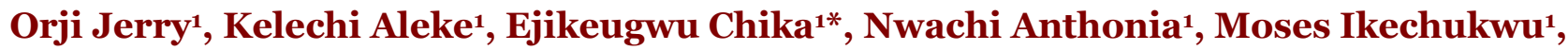 \\ Eluu Stanley ${ }^{2}$ and Ugbo Emmanuel ${ }^{1}$
}

${ }^{1}$ Department of Applied Microbiology, Faculty of Sciences, Ebonyi State University, P.M.B. O53, Abakaliki, Ebonyi State, Nigeria ${ }^{2}$ Department of Biotechnology, Faculty of Sciences, Ebonyi State University, Abakaliki, P.M.B o53, Ebonyi State, Nigeria

*Corresponding author.

\begin{tabular}{|c|c|}
\hline Abstract & Article Info \\
\hline $\begin{array}{l}\text { Cellulase is an inducible enzyme complex involving synergistic action of } \\
\text { endoglucanase, exoglucanase and cellubiase; and it is produced by a number of bacteria, } \\
\text { actinomycetes and fungi including Trichoderma species and Aspergillus species. } \\
\text { However, fungi are the most common producer of cellulose used for industrial } \\
\text { processes. Corn cob which is composed mainly of cellulose is a major component of } \\
\text { agricultural and domestic waste in many parts of the world. It can be converted to } \\
\text { energy in form of bioethanol as an effective and efficient means of waste management. } \\
\text { Production of cellulase was induced in the fungi Aspergillus niger by growing it in } \\
\text { mineral salt medium containing alkali pre-treated corn cobs. The cellulases were } \\
\text { partially purified. Alkali pre-treated corn cob was hydrolysed with the partially purified } \\
\text { cellulases and the product of hydrolysis was fermented using Saccharomyces cerevisiae } \\
\text { and Zymomonas mobilis. The cellulosic hydrolysate yielded } 1.78 \mathrm{gl}^{-1} \text { sugars which } \\
\text { produced } 9.10 \mathrm{gl}^{-1} \text { ethanol fermentation using Zymomonas mobilis, compared to ethanol } \\
\text { yield at } 8.20 \text { gl }{ }^{-1} \text { using Saccharomyces cerevisiae. Alkali pre-treated corn cob, } \\
\text { hydrolysed with cellulases of A. niger is a suitable feedstock for bioethanol production. } \\
\text { Also Z. mobilis is the most relevant organism when compared to Saccharomyces } \\
\text { cerevisiae for industrial bioethanol production. Agricultural and industrial wastes litter } \\
\text { the environment and cause environmental pollution. But the conversion of these } \\
\text { materials into useful products (especially by microbial activity including those mediated } \\
\text { by cellulase-activity) is critical to assuaging or preventing the environmental problems } \\
\text { that these wastes cause. Thus, our study has presumptively shown that corncob } \\
\text { hydrolyzed with cellulase extracted from A. niger with the help of Z. mobilis and S. } \\
\text { cerevisiae isolated from palm wine could be a putative source of bioethanol. Further } \\
\text { study is therefore needed to scale up this protocol to a large scale industrial production } \\
\text { for local bioethanol production in this region. }\end{array}$ & $\begin{array}{l}\text { Ke y w o r d s } \\
\text { Aspergillus niger } \\
\text { Biofuels } \\
\text { Corncobs } \\
\text { Fermentation } \\
\text { Saccharomyces cerevisiae } \\
\text { Zymomonas mobilis }\end{array}$ \\
\hline
\end{tabular}

\section{Introduction}

The importance of ethanol as a clean and safe transportation fuel has increased with the anticipated shortage of fossil fuel reserves and increased air pollution caused by the usage of fossil fuels (Lin and Tanaka, 2006; Solomon et al., 2007). Fuels derived from cellulosic biomass offer an alternative to conventional energy sources that supports national economic growth, national energy security, and 
environmental sustainability. However a dramatic increase in ethanol production using the current starchbased technology may not be practical in Nigeria because it will compete for the limited agricultural land needed for food and feed production, thus affecting food security. Lignocellulosic biomass is a cheap, renewable, abundantly available resource (Hansen et al., 2005), and its conversion to glucose and other fermentable sugars has been considered to be an attractive route for ethanol production (Cao et al., 1996; Cazetta et al., 2007). In Nigeria, corn is processed to a variety of diets including pap which is a major diet used for weaning, and the capacity for corn production in Nigeria is high. Corn cobs form about 30 $\%$ of maize agro-wastes of which application in bioethanol industry are the focus of many researches aimed at achieving an effective and efficient waste management scheme (Olsson and Hahn-Hägerdal, 1996).

Currently the corn cobs (which contain 32.3-45.6\% cellulose, $39.8 \%$ hemicelluloses and 6.7-13.9\% lignin) are burnt as fuel in households of peasant rural farmers which leads to severe environmental constraints. But it can be converted to fermentable sugar for ethanol production via enzymatic and microbial action. Physicochemical pre-treatment, cellulose saccharification and glucose fermentation to ethanol are the three main stages involved in the production of bioethanol from corn cobs (Jeffries and Jin, 2004), and the hydrolysis of cellulose has been achieved with dilute acids under high temperature and pressure and with concentrated acids at low temperature and atmospheric pressure. Largeamounted, concentrated agricultural waste corn cob is generated annually in Nigeria, and often causes environmental pollution due to the lack of its effective utilization. Thus, this study determined the production of bioethanol from corncob through the action of cellulase of Aspergillus niger and combined activity of Zymomonas mobilis and Saccharomyces cerevisiae isolated from palm wine.

\section{Materials and methods}

\section{Sample collection}

A freshly tapped palm wine was purchased from a palm wine market at Ntezi, Ishielu Local Government Area, Ebonyi State with the use of a sterile container. The palm wine was used fresh after it was tapped. A sterile polythene bag was used to collect a decaying corncob at a dumpsite in Abakaliki metropolis. The corncob and palm wine was taken to the microbiology laboratory of Ebonyi State University, Abakaliki where they were further analyzed.

\section{Isolation of microorganisms}

The test organisms including Aspergillus niger, Zymomonas mobilis and Saccharomyces cerevisiae were isolated based on standard microbiology techniques (Cheesbrough, 2006). Briefly, Twenty (20) ml volume of the palm wine was centrifuged at $5000 \mathrm{rpm}$ for 10 minutes, and a loopful of the palm wine sediment was aseptically collected using a wire loop, and this was inoculated on already prepared Sabouraud dextrose agar (SDA) and potato dextrose agar (PDA) growth media supplemented with $300 \mathrm{mg}$ of Ketoconazole and $500 \mathrm{mg}$ of chloramphenicol to inhibit the growth of saprophytic fungi and bacteria respectively.

After inoculation, the Petri dishes were packed in an anaerobic jar, and incubated at $37^{\circ} \mathrm{C}$ for $48 \mathrm{hrs}$ for fungal growth and isolation. Recovered suspect colonies were subcultured onto freshly prepared culture media plates for the isolation of pure isolates. The identification and characterization of the pure bacterial isolates were based on morphological, physiological and biochemical tests as was previously described (Cheesbrough, 2006; Oyeleke et al., 2012).

\section{Isolation of Aspergillus niger from dumpsite corncob}

A sterile polythene bag was used to collect a decaying corncob at a dumpsite in Abakaliki. The corncob was taken to the laboratory after which $10 \mathrm{~g}$ of corn cob was immersed in $100 \mathrm{ml}$ of distilled water. A four (4)-fold serial dilution of remnant of corncob water immersion was carried out and cultivation was done on potato dextrose agar (PDA). Pour-plate method was used to inoculate the growth medium prepared with $1 \mathrm{ml}$ of the diluted sample; and were incubated for a period of 4 days at $37^{\circ}$ C. Sub-culturing was carried out until pure cultures of Aspergillus niger was obtained and the pure Aspergillus niger colony was used to produce cellulase. After 4 days of cultivation, a small portion of the mycelia growth was carefully picked with the aid of a sterile wire loop and placed on a drop of lactophenol cotton blue on a microscope slide and covered with a cover slip. The slide was examined under the microscope with (40x) objective lens for morphological examination as described by Cheesbrough (2006). The isolates were characterized based on the colour of aerial, shape and kind of asexual spores, and the characteristics of spore head. 


\section{Screening of Aspergillus niger for cellulase activity}

A loopful of growth culture of isolated colonies was inoculated on $3.9 \mathrm{~g}$ of Potato dextrose Agar (PDA) mixed with $0.2 \mathrm{~g}$ Carboxyl Methyl Cellulose (CMC), dissolved in $100 \mathrm{ml}$ distilled water. The PDA plates were incubated for 3 days at $37^{\circ} \mathrm{C}$ for Aspergillus isolate and observed for growth. To undertake ammonia steeping, 20 $\mathrm{g}$ of milled corn cobs of particle size of $2 \mathrm{~mm}$ was mixed with $100 \mathrm{ml} 2.9 \mathrm{M} \mathrm{NH} \mathrm{NH}_{4} \mathrm{OH}$ solution in a $250 \mathrm{ml}$ Erlenmeyer flask. The mixture was then incubated in a shaker for $24 \mathrm{hr}$ at $30^{\circ} \mathrm{C}$. The content was filtered using a $2 \mu \mathrm{m}$ Whatman filter paper into $250 \mathrm{ml}$ Erlenmeyer flask. It was further rinsed twice using distilled water. The corncobs were then dried at $30^{\circ} \mathrm{C}$ in an oven overnight.

\section{Production of enzyme}

Spores of Aspergillus niger were harvested by flooding 1 week old stock culture on agar slants with sterile distilled water $(5 \mathrm{ml})$ as was previously described (Martin et al., 2002). The inoculums medium $(100 \mathrm{ml})$ comprised of Mandels mineral salt, was inoculated with the entire spore suspension and incubated on a rotary shaker (150 $\mathrm{rpm})$ at room temperature for $72 \mathrm{hrs}$. Each $250 \mathrm{ml}$ flask containing $100 \mathrm{ml}$ of Mandels mineral salt medium, into which was incorporated $10 \mathrm{~g}$ of cellulosic materials i.e. alkali pre-treated and untreated corn cob; and Carboxyl methyl cellulose (CMC). The medium was inoculated with inoculums culture $(5 \mathrm{ml})$ containing approximately $4.6 \times 10^{6}$ spores $/ \mathrm{ml}$ of the fungi and incubated at $28^{\circ} \mathrm{C}$ on a gyratory shaker (150 rpm) for 10 days. Enzyme filtrates were obtained, after which cultures were centrifuged and stored at $-10^{\circ} \mathrm{C}$ until required.

\section{Assay for Cellulase activities}

Endoglucanase activity - Carboxyl methyl cellulose: Reaction mixture comprising of $0.5 \mathrm{ml}$ carboxyl methyl cellulose $(2 \% \mathrm{w} / \mathrm{v})$ in $0.05 \mathrm{M}$ citrate buffer, $\mathrm{pH} 4.8$ and $0.5 \mathrm{ml}$ culture filtrate in test tubes. Mixture was incubated at $50^{\circ} \mathrm{C}$ for $1 \mathrm{hr}$. After incubation $1 \mathrm{ml}$ of dinitrosalicyclic acid reagent was added to stop the reaction. The reactants in test tubes were boiled for 5 mins in boiling water bath and transferred to cold water bath. $10 \mathrm{ml}$ of distilled water was added and absorbance was measured at $540 \mathrm{~nm}$ in spectrophotometer. Amount of reducing sugar was read from a curve obtained by plotting value of absorbance against concentration. One unit of enzyme activity is defined as the amount of enzyme that released $1 \mu \mathrm{m}$ of reducing sugar.

\section{Bioethanol production}

Bioethanol production from the corncob was microbiologically analyzed using previous methodology; and the methods employed in this assay included enzyme hydrolysis, fermentation and distillation process as was previously described (Yanase et al., 2005; Oyeleke et al., 2012).

\section{Hydrolysis of corn cob with the partially purified cellulose of isolated fungi}

The method of Oyeleke et al. (2012) was employed. Citrate buffer $(100 \mathrm{ml})$ containing alkali treated corn cob $(10 \% \mathrm{w} / \mathrm{v})$ in $250 \mathrm{ml}$ Erlenmeyer flask was inoculated with $10 \mathrm{ml}$ of the partially purified filtrate and incubated at $50^{\circ} \mathrm{C}$ for $7 \mathrm{hrs}$. Samples $(1 \mathrm{ml})$ was withdrawn aseptically from flask at $1 \mathrm{hr}$ interval and analysed for reducing sugar by the DNSA method to determine the optimum time in hours for cellulose digestion of corn cob. The hydrolysate was then used for fermentation to produce ethanol.

\section{Fermentation of the products of corncob digestion to ethanol}

The fermentation of the products of corncob digestion to ethanol was carried out by a previously described methodology (Oyeleke et al., 2012). Yeast peptone dextrose broth $(100 \mathrm{ml})$ in $250 \mathrm{ml}$ Erlenmeyer flask was inoculated with pure colonies of yeast from agar slant with the aid of an inoculating loop. This was incubated at $28^{\circ} \mathrm{C}$ on gyratory shaker at $150 \mathrm{rpm}$ for $48 \mathrm{hrs} .0 .3 \mathrm{~g}$ malt extract, $0.3 \mathrm{~g}$ yeast extract, $2 \mathrm{~g}$ glucose, $0.5 \mathrm{~g}$ peptone and $0.002 \mathrm{~g}$ of actidone dissolved in water was inoculated with pure colonies of Zymomonas mobilis from agar slant with the aid of inoculating loop. The fermentation broth $(100 \mathrm{ml})$ comprising of $(\% \mathrm{w} / \mathrm{v})$, Peptone, $8 \mathrm{~g}$; yeast extract, $8 \mathrm{~g}$; and the product of hydrolysis of corn cob as the fermenting sugar. The broth $(80 \mathrm{ml})$ was filled into a $100 \mathrm{ml}$ sealable bottle, sterilized in an autoclave and inoculated with $10 \mathrm{ml}$ of each of the inoculums. The bottles were sealed with the aid of an adhesive tape and incubated at $28^{\circ} \mathrm{C}$ for a period of $8-$ $48 \mathrm{hrs}$. Bottles were removed at $8 \mathrm{hrs}$ intervals to determine the amount of ethanol produced and the residual sugar in the medium.

\section{Determination of ethanol concentration by the acidified dichromate/thiosulphate titration method}

The fermented broth was assayed for ethanol using the acidified dichromate/thiosulphate titration method. Ten 
$\mathrm{ml}$ acid dichromate solution (0.01 $\mathrm{M}$ in 5.0 $\mathrm{M}$ sulphuric acid) was placed in $250 \mathrm{ml}$ Erlenmeyer flask. This was connected to $10 \mathrm{ml}$ of fermented broth in another $250 \mathrm{ml}$ Erlenmeyer flask which was placed in water bath set at $80^{\circ} \mathrm{C}$. The set up was allowed to stand for $3 \mathrm{hrs}$, during which ethanol produced by the fermentation of the broth evaporated into the acid dichromate solution. All the flasks were fixed with rubber stopper and sealed with wax to avoid leakages. After the incubation period, the set up was dismantled, $100 \mathrm{ml}$ distilled water and $1.0 \mathrm{ml}$ Potassium iodide $(1.2 \mathrm{M})$ was added to the dichromate solution. This was then titrated with Sodium thiosulphate $(0.03 \mathrm{M})$ until the brown colour turned yellow, at which point $1 \%$ starch solution $(1 \mathrm{ml})$ was added as indicator of iodine, and further titrated until the blue colour fades. Three flasks consisting of $10 \mathrm{ml}$ acid dichromate was set up as blanks and titrated first so as to monitor the volume of thiosulphate required. The difference between thiosulphate used in the titration of the blank and that of the sample was used in calculating the amount of ethanol.

\section{Determination of residual sugar in the fermentation medium}

The amount of sugar in the fermentation medium after each period of fermentation was determined following the DNSA method of Miller (1959). Dinitrosalicylic acid (DNSA) reagent $(1 \mathrm{ml})$ was added to an aliquot $(1 \mathrm{ml})$ of the fermentation medium in a test tube and properly mixed. The mixture was boiled for 5 mins and cooled under running tap water. $5 \mathrm{ml}$ of $40 \%$ Rochelle salt solution was added to the mixture and absorbance read in spectrophotometer at $540 \mathrm{~nm}$. Amount of reducing sugar was read from a standard glucose curve and expressed as $\mathrm{mg} \mathrm{ml}^{-1}$.

\section{Results}

\section{Cellulase production by Aspergillus niger}

The result of this investigation showed that there was progressive increase in enzyme activity from 24 to $144^{\text {th }}$ $\mathrm{hr}$ after incubation. The highest cellulase activity was obtained on the $5^{\text {th }}$ day $(2.30 \mathrm{mg} / \mathrm{ml} / \mathrm{sec})$ and the least on the first day $(1.3 \mathrm{mg} / \mathrm{ml} / \mathrm{sec})$ this corresponds to the day with the highest and lowest biomass activities (Fig. 1).

\section{Effect of cellulase dosage on hydrolysis of corn cob powder}

Fig. 2 shows the results of hydrolysis experiments performed with $100 \mathrm{gl}^{-1}$ substrate and different dosage of the crude cellulose at $\mathrm{pH} 4.8$ and $50^{\circ} \mathrm{C}$. The reducing sugar concentration increased sharply with an increase in the cellulase dosage.

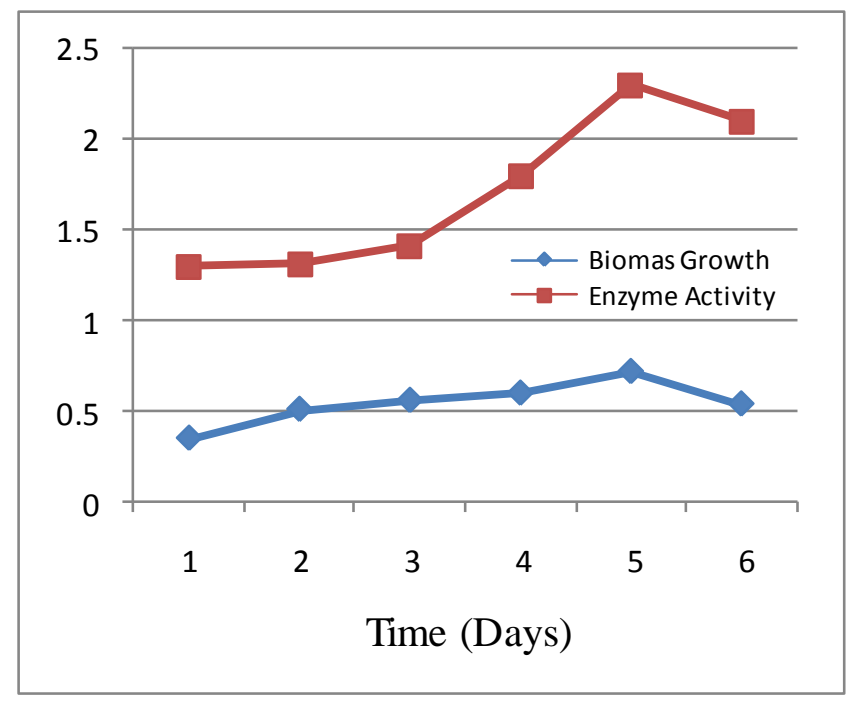

Fig. 1: Production of cellulase by Aspergillus niger.

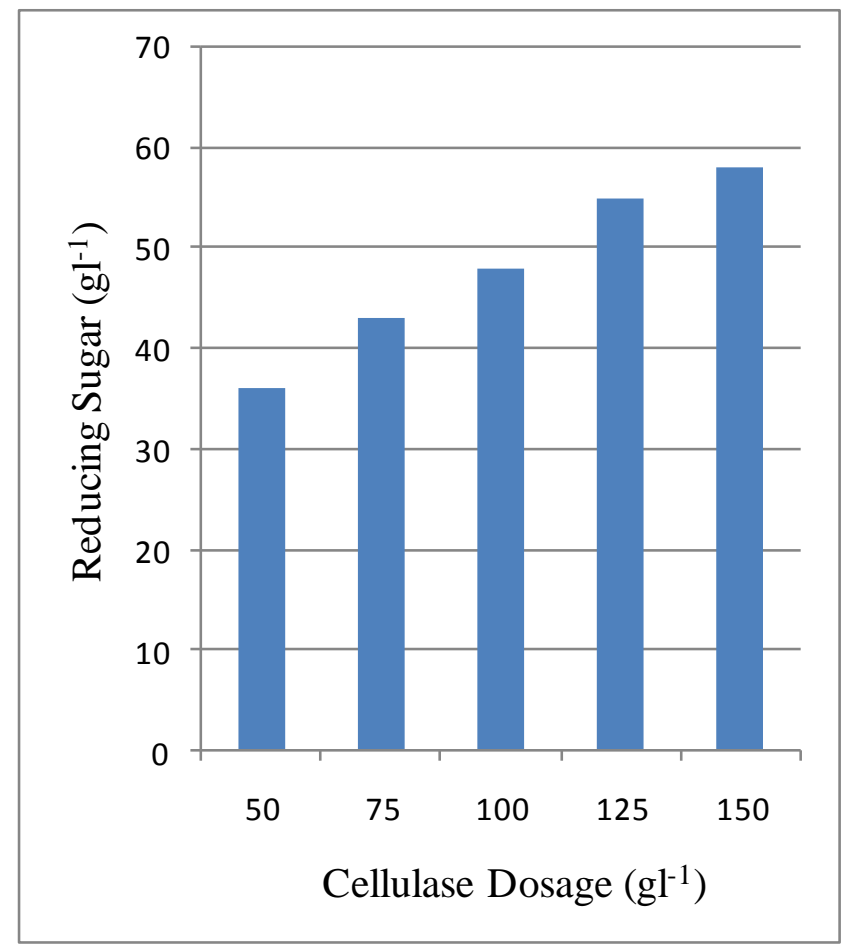

Fig. 2: Effect of cellulase dosage on hydrolysis of corncob.

\section{Time course for saccharification of corn cob powder}

The result of this experiment showed that there was an increase in saccharification of corn cob from 0 to $7^{\text {th }}$ hrs. The increase was steeper up to $5^{\text {th }}$ hr than from 5 to $7^{\text {th }}$ hrs (Fig. 3). 


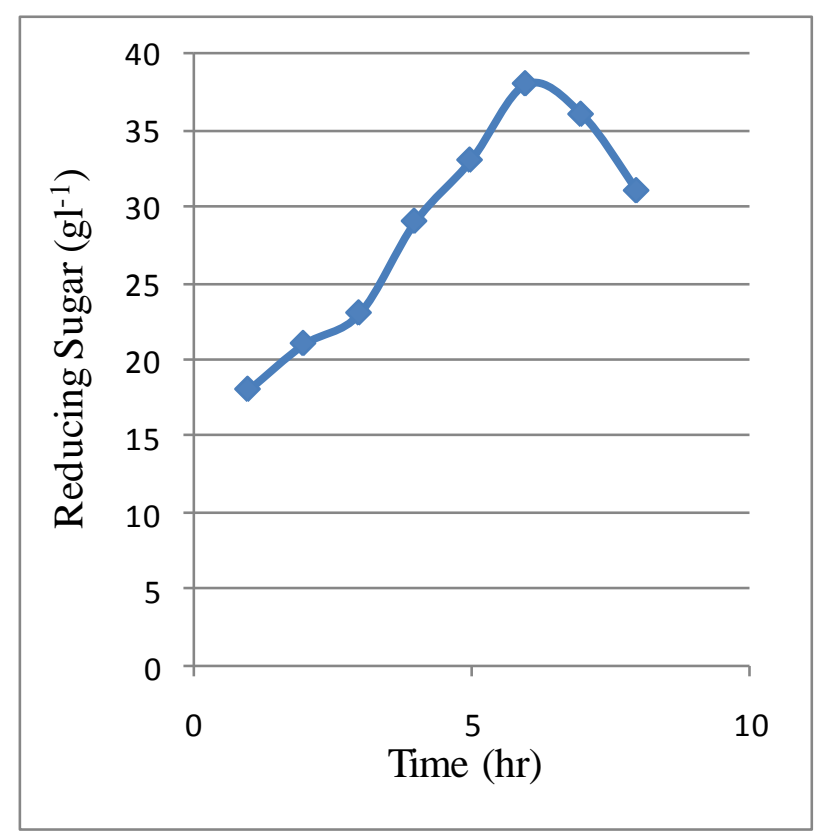

Fig. 3: Time course for Saccharification of corn cob powder.

Production of bioethanol with the use of Saccharomyces cerevisiae

The result obtained during production of ethanol with the use of $S$. cerevisiae is shown in Figure 4. The result showed that the value of the microbial cell density increased drastically from $8^{\text {th }}$ hr up to the $32 \mathrm{nd} \mathrm{hr}$, at which point a lag phase of its growth was observed. Also the result showed an increase in ethanol concentration from $0.7 \mathrm{gl}^{-1}$ at the $8^{\text {th }} \mathrm{hr}$ to $8.3 \mathrm{gl}^{-1}$ at the $40^{\text {th }} \mathrm{hr}$, after which there was decrease in its concentration. The result also showed that the sugar concentration inversely decrease with an increase in ethanol concentration observed at 8-16 hrs and 24-48 hrs intervals is the result of glucose utilization by $S$. cerevisiae either for biomass or ethanol production.

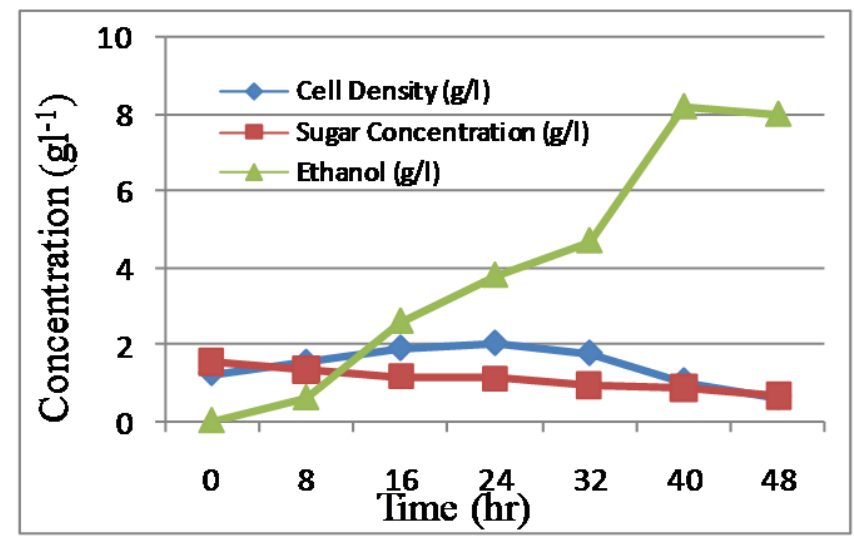

Fig. 4: Production of ethanol with the use of S. cerevisiae.
Bioethanol production from corn cob using Zymomonas mobilis

Fig. 5 shows the results obtained during ethanol production from corncob using $Z$. mobilis. The result shows a drastic increase in ethanol concentration with a corresponding decrease in sugar concentration. It also shows a simultaneous increase in the microbial cell density with increase in ethanol concentration. Also the decrease in sugar concentration observed at $0-24 \mathrm{hr}$ is the result of glucose utilization by Z. mobilis either for biomass or ethanol production.

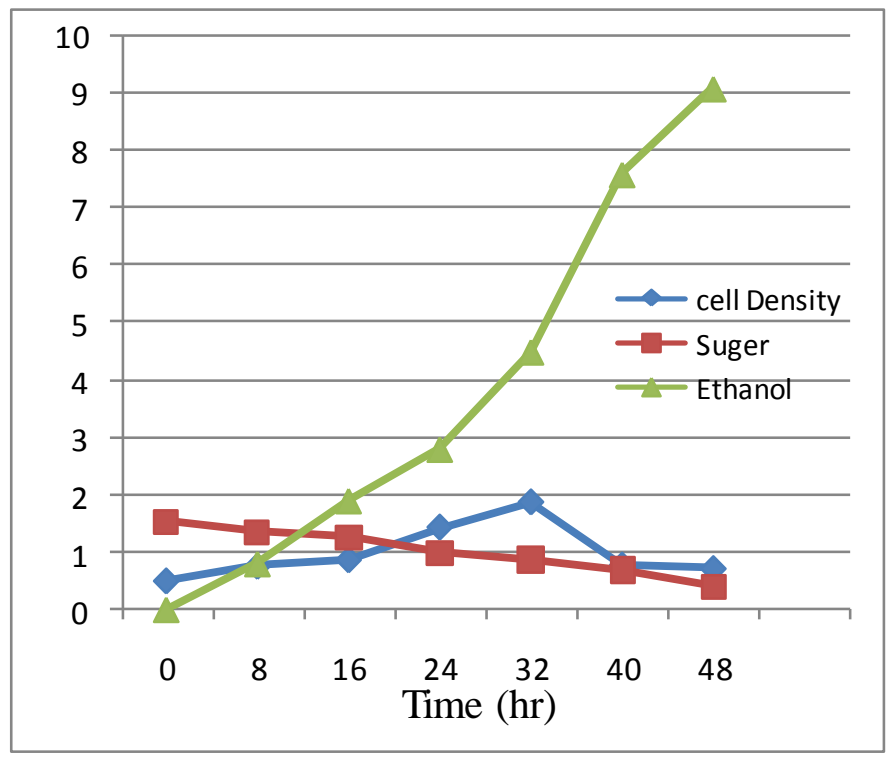

Fig. 5: Bioethanol production from Corncob using Z. Mobilis.

\section{Discussion}

This present day study evaluated the production of bioethanol from corncob hydrolysed by the cellulase activity of $A$. Niger; and using $Z$. mobilis and $S$. cerevisiae isolated from palm wine as an alternative source of feed stock for the local production of biofuels in this region. The increasing phenomenon of climate change and global warming (which are directly or indirectly linked to the use of fossil fuels) is affecting several human activities including agriculture. However, the development and use of alternative sources of fuels from natural sources such as corncob wastes (as investigated in this study) hold sway to the local production of cost-effective approaches of biofuel production. The results obtained from this study showed that Saccharomyces cerevisiae and Zymomonas mobilis are abundant in palm wine. Natural strains of the yeast have most often been found were fermentation occurs; 
and these organisms play critical roles in the conversion of sugar to alcohol (Mortimer and Johnston, 2000). Z. mobilis abounds in palm wine as a dominant alcohol producing bacteria; and it has also shown a high growth rate and tolerance to ethanol as well as being amenable to engineering. Zymomonas species being an anaerobic Gram negative rod uses only Embden Meryerhoff pathway, and thus the organism requires no oxygen for its metabolic processes (Yanase et al., 2005).

Fermentation systems using Zymomonas species would require no sparging and/or aeration like yeast Katzen and Schell, 2006); and this helps to cut down on fermentation cost. A. niger, the best cellulolytic fungi isolated from corncob sampled from dumpsite at Abakaliki was assayed for enzyme activity; and the result showed a progressive increase in enzyme activity. Cellulase is an induced enzyme; and its production increased with increase in fungal biomass over the incubation period and as simple sugar in the substrate diminishes (Lynd, 1996). The result obtained also showed that there was increase in saccharification from 0 to $10^{\text {th }} \mathrm{hr}$. The increase was steeper up to $6^{\text {th }} \mathrm{hr}$ than from 6 to the $10^{\text {th }}$ $\mathrm{hr}$. The slowdown in rate for hydrolysis may be due to the action of the enzymes been slowed down by obstacles that interfere with their path or a loss in activity and/or processivity making them less effective (Yang et al., 2006). The rate of Saccharification is directly proportional to substrate concentration up to the optimal substrate concentration. This is because random collisions between the substrate and enzyme active sites happen more frequently. As the cost of cellulase is high, the cellulase dosage should be minimized as much as possible (Cao et al., 1996). During fermentation, the ethanol in the product increased while the reducing sugar decreased as a result of the fact that during fermentation the yeast (S. cerevisiae) utilized the sugar as a source of carbon and energy, and ethanol is produced as a result (Gunasekaran and Chandra, 1999). There was increase in ethanol production over the period of fermentation, likewise as increase in saccharification making glucose available to the microorganisms ( $S$. cerevisiae and $Z$. mobilis) for fermentation. Previous studies reported that enzymatic hydrolysis of the solid fraction has a large control over the total rate of ethanol production in simultaneous saccharification and fermentation (Olofsson et al., 2008). A high ethanol yield (49 \%) was achieved in the fermentation of biomass hydrolysate by the bacterium $Z$. mobilis compared to the yield obtained with $S$. cerevisiae which $(43 \%)$ in our study. S. cerevisiae, however, consumes sugar for growth and production of other metabolites. Ethanol production in this study is comparable to previous studies where varying rates of ethanol where produced from local wastes (Olofsson et al., 2008; Agarwal et al., 2011; Cao et al., 1996). Moreover since growth commences during the aerobic phase, some amount of sugar gets used up before the anaerobic stage which is characterized by ethanol production.

Conclusively, ethanol was produced from corncob wastes via the combined fermentative and/or microbial activities of A. niger, Z. Mobilis, S. Cerevisiae; and corncobs was affirmed as viable feedstock for energy production. Also corncob hydrolyzed by cellulases of $A$. niger was productive in terms of ethanol yield and can therefore be harnessed in biofuel production. The present study also showed that palm wine is a good medium for the propagation of ethanogenic microorganisms (i.e. ethanol-producing organisms) including Z. Mobilis; and that ethanol could be produced from industrial/domestic or agricultural wastes like corncobs. Z. mobilis is the most relevant organism when compared with $S$. cerevisiae for industrial production of bioethanol as a result of its higher sugar uptake and ethanol yield, as well as its higher ethanol tolerance - which are all deficient in S. cerevisiae. The production of ethanol from agricultural wastes like corncobs will help in environmental sustainability especially in the area of controlling environmental pollution as well as making available sustainable and clean sources of energy such as biofuels.

\section{Conflict of interest statement}

Authors declare that they have no conflict of interest.

\section{References}

Agrawal, M., Mao, Z., Chen, R.R., 2011. Adaptation yields a highly efficient xylose-fermenting Zymomonas mobilis strain. Biotechnol. Bioeng. 108(4), 777-785.

Cao, N.J., Krishnan, M.S., Du, J.X., Gong, C.S., Ho, N.W.Y., 1996. Ethanol production from corn cob pretreated by the ammonia steeping process using genetically engineered yeast. Biotechnol. Lett. 18, 1013-1018.

Cazetta, M.L., Celligoi, M.A.P.C., Buzato, J.B., Scarmino, I.S., 2007. Fermentation of molasses by Zymomonas mobilis: Effects of temperature and sugar concentration on ethanol production. Bioresour. Technol. 98, 2824-2828.

Cheesbrough, M., 2006. Medical Laboratory Manual. Tropical Health Technology, Low Priced Edition. Doddington, Cambridgeshire, England. pp.18-50.

Gunasekaran, P., Chandra R. K., 1999. Ethanol fermentation technology - Zymomonas mobilis. Curr. Sci. 77(1), 56-68. 
Hansen, A.C., Zhang, Q., Lyne, P.W.L., 2005. Ethanol-diesel fuel blends a review. Bioresour. Technol. 96, 277-285.

Jeffries, T.W., Jin, Y.S., 2004. Metabolic engineering for improved fermentation of pentoses by yeasts. Appl. Microbiol. Biotechnol. 63(5), 495-509.

Katzen, R., Schell, D.J., 2006. Lignocellulosic feedstock biorefinery: History and plant development for biomass hydrolysis. Appl. Microbial Biotech. 65, 129-138.

Lin, Y., Tanaka, S., 2006. Ethanol fermentation from biomass resources: current state and prospects. Appl. Microbiol. Biotechnol. 69, 627-642.

Lynd, L.R., 1996. Overview and evaluation of fuel ethanol from cellulosic biomass: technology, economics, the environment, and policy. Ann. Rev. Energy Environ. 21, 403-465.

Martin, C., Galbe, M., Wahlbom, C.F., Hagerdal, B.H., Jonsson, L.J., 2002. Ethanol production from enzymatic hydrolysates of sugarcane bagasse using recombinant xylose-utilising Saccharomyces cerevisiae. Enz. Microb. Technol, 31, 274-282.

Miller, G.L., 1959. Dinitrosalicylic acid reagent fro determination of reducing sugar. Anal. Chem. 80, 476480 .
Mortimer, R.K., Johnston, J. R., 2000. Genealogy of principal strains of the yeast genetic stock center. Genet. 113, 3543.

Olofsson, L., Hahn-Hägerdal, B., 1996. Fermentation of lignocellulosic hydrolysates for ethanol fermentation. Enzyme Microb. Technol. 18, 312-331.

Olsson, L., Hahn-Hägerdal, B., 1996. Fermentation of lignocellulosic hydrolysates for ethanol fermentation. Enzyme Microb. Technol. 18, 312-331.

Oyeleke, S.B., Dauda, B.E.N., Oyewole, O.A., Okoliegbe, I.N., Ojebode, T., 2012. Production of bioethanol from cassava and sweet potato peels. Adv. Environ. Biol. 6(1), 241-245.

Solomon, B. D., Barnes, J. R., Halvorsen, K. E., 2007. Grain and cellulosic ethanol: History, economics, and energy policy. Biomass Bioener. 31, 416-425.

Yanase, H., Nozaki, K., Okamoto, K., 2005. Ethanol production from cellulosic materials by genetically engineered Zymomonas mobilis. Biotechnol. Lett. 27, 259263.

\section{How to cite this article:}

Orji, J., Kelechi, A., Ejikeugwu, C., Nwachi, A., Moses, I., Eluu, S., Ugbo, E., 2016.

Bioethanol production from corncob hydrolysed by cellulase of Aspergillus niger using Zymomonas mobilis and Saccharomyces cerevisiae isolated from palm wine. Int. J. Curr. Res. Biosci. Plant Biol. 3(1), 39-45. doi: http://dx.doi.org/10.20546/ijcrbp.2016.301.004 